Schwendel, Arved ORCID:

https://orcid.org/0000-0003-2937-1748, Fuller, lan C. and Death, Russell G. (2010) Assessing DEM interpolation methods for effective representation of upland stream morphology for rapid appraisal of bed stability. River Research and Applications, 28 (5). pp. 567-584.

Downloaded from: http://ray.yorksj.ac.uk/id/eprint/2619/

The version presented here may differ from the published version or version of record. If you intend to cite from the work you are advised to consult the publisher's version: https://doi.org/10.1002/rra.1475

Research at York St John (RaY) is an institutional repository. It supports the principles of open access by making the research outputs of the University available in digital form. Copyright of the items stored in RaY reside with the authors and/or other copyright owners. Users may access full text items free of charge, and may download a copy for private study or non-commercial research. For further reuse terms, see licence terms governing individual outputs. Institutional Repository Policy Statement

\title{
RaY
}

Research at the University of York St John

For more information please contact RaY at ray@yorksj.ac.uk 
River Research and Applications

WILEY

\section{Assessing DEM interpolation methods for effective representation of upland stream morphology for rapid appraisal of bed stability}

\begin{tabular}{|c|c|}
\hline Journal: & River Research and Applications \\
\hline Manuscript ID: & RRA-09-0288.R2 \\
\hline Wiley - Manuscript type: & Research Article \\
\hline $\begin{array}{r}\text { Date Submitted by the } \\
\text { Author: }\end{array}$ & $\mathrm{n} / \mathrm{a}$ \\
\hline Complete List of Authors: & $\begin{array}{l}\text { Schwendel, Arved; Massey University, Institute of Natural } \\
\text { Resources - Ecology } \\
\text { Fuller, Ian; Massey University, Geography } \\
\text { Death, Russell; Massey University, Institute of Natural Resources - } \\
\text { Ecology }\end{array}$ \\
\hline Keywords: & $\begin{array}{l}\text { DEM interpolation, morphological budgeting, Surfer, channel form, } \\
\text { gravel-bed river, substrate stability, triangulation, kriging }\end{array}$ \\
\hline
\end{tabular}

\section{SCHOLARONE ${ }^{\text {m }}$ Manuscripts}




\title{
Assessing DEM interpolation methods for effective representation of upland stream morphology for rapid appraisal of bed stability
}

\author{
Arved C. Schwendel ${ }^{\mathrm{a} *}$, Ian C. Fuller ${ }^{\mathrm{b}}$, Russell G. Death ${ }^{\mathrm{a}}$ \\ ${ }^{\text {a }}$ Ecology Group, Institute of Natural Resources, Massey University, Private Bag \\ 11222, Palmerston North 4442, New Zealand \\ ${ }^{\mathrm{b}}$ Geography Programme, School of People, Environment \& Planning, \\ Massey University, Palmerston North, New Zealand \\ * Corresponding author: Email: A.C.Schwendel@massey.ac.nz, phone +64 (0)6 \\ 3504885, fax +64 (0)6 3505623
}




\begin{abstract}
Digital elevation models (DEMs) of river channels, built by interpolation between a sample of topographic survey points, are widely used to represent surfaces and to derive land-surface parameters. Differencing between successive DEMs permits quantification of change, which in gravel-bed rivers is used to construct a morphological budget of lower bound estimates of sediment flux and bed-stability surrogate. Choice of DEM interpolation method strongly influences DEM quality and realistic representation of channel forms. When comparing morphological budgets between multiple contrasting reaches, e.g. for rapid ecological appraisal, an effective and consistent means of DEM construction is required to avoid digitally generated inconsistencies. An appropriate interpolation method should be suitable for accurate representation of channels contrasting in substrate and hydraulic conditions, surveys of varying data density and distribution, and avoidance of site specific parameterisation. This paper investigates representation of channel form using a series of DEMs generated within Surfer ${ }^{\circledR}$ by triangulation with linear interpolation, natural neighbours, point kriging, universal kriging, multiquadratic radial basis function, modified Shepard's method and inverse distance to a power on the example in 4 reaches of mountain streams in New Zealand. These reaches represent a diversity of channel forms, substrate and hydraulic properties. DEMs from triangulation with linear interpolation revealed consistently the best results and this method is recommended for geomorphological and ecological studies of multiple reaches. The main advantage over point kriging and radial basis function is better representation of channel margins and bedforms without introduction of breaklines, while it outperforms natural neighbours in honouring measured points.
\end{abstract}

\title{
KEYWORDS
}

DEM, interpolation, morphological budgeting, Surfer, channel form, gravel-bed river, substrate stability, triangulation, kriging 


\section{INTRODUCTION}

Fluvial geomorphology and hydrology can provide techniques and concepts that allow understanding of the complex hydrogeomorphological underpinnings of stream ecology (Poole, 2010). Consequently these disciplines share methods and tools, e.g. in geomorphology, hydrology and ecology DEMs are often used to represent topography or derive land-surface parameters. DEMs of riverine landscapes are of particular interest for mapping (e.g. pattern of morphological change), modelling (e.g. flow routing) and calculating of sediment budgets. Morphological changes and sediment budgets are determined from the difference in surface elevation of subsequent DEMs. Morphological budgeting is a widely applied and accepted method for quantifying areas of deposition or erosion and for determining lower-bound sediment fluxes within a gravel- and cobble-bed river reach (e.g. Ashmore and Church, 1998; Brasington et al., 2000; Fuller et al., 2005). In recent years the approach has shifted from budgets calculated from planform and/ or cross-sectional measurements (Brewer and Passmore, 2002; Fuller et al., 2002; Martin and Church, 1995) to digital elevation model (DEM) based estimations (Brasington et al., 2003; Chappell et al., 2003; Eaton and Lapointe, 2001; Fuller et al., 2003a; Fuller et al., 2003b; Lane et al., 1994; Westaway et al., 2000).

The pattern of scour and fill within a reach identified for instance by morphological budgeting can be used in ecology to assess intensity and spatial extent of physical disturbance, to examine spawning habitat quality and to investigate the availability of stable refugia for stream organisms during floods (Matthaei and Townsend, 2000; Wheaton et al., 2010a). Additionally sediment budgets at various scales (e.g. patch, riffle or entire reach) can be employed as a measure of bed stability (Schwendel et al., in revision). Morphological budgeting also has the potential to replace scour chains in research on lotic ecosystems having the advantage of lower invasiveness and higher spatial resolution (Schwendel et al., 2010a).

Surveys to collect data used to create DEMs can be airborne (e.g. photogrammetry, laser altimetry) (Brasington et al., 2003; Ham and Church, 2000; Lane, 2001; Lane et al., 2003; Westaway et al., 2001) or ground based (photogrammetry, tacheometry, including, most recently, terrestrial laser scanning) (Fuller et al., 2002; Heritage et al., 1998; Lane et al., 1994; Milan et al., 2007) depending on the size of the reach and available technology. Airborne LiDAR and 
terrestrial laser scanning (TLS) can provide high resolution surveys but vegetation (for LiDAR) and deeper water constrains application because of limited light penetration of water. The latest generation of LiDAR overcomes the latter problem by emitting also green light, which is not absorbed by water, but to date expense and availability limit its application. More conventional techniques, such as terrestrial tacheometry are widely available and more suitable for subaqueous surveys although their lower resolution imposes some limits in assessment of surface roughness. This needs to be accommodated by terrain sensitive data acquisition and a suitable DEM interpolation method.

Measurement of 3D coordinates on a surface is afflicted with several kinds of error, notably precision, accuracy and reliability of measurements (Lane et al., 1994). Precision depends on the instruments used and surface roughness, while accuracy describes systematic errors such as verticality of the survey pole (Lane et al., 1994). Gross errors or blunders control data reliability and are difficult to detect. Usually the irregular network of surveyed points is transformed to a regular grid (interpolation) which facilitates the comparison of DEMs from repeated surveys of the river bed. However, this involves error associated with DEM accuracy (sensu Wood and Fisher, 1993) which is affected by the interpolation algorithm, spatial structure of altitude as well as density and spatial distribution of data points (Brasington et al., 2000; Chaplot et al., 2006; Desmet, 1997; Fisher and Tate, 2006). Hence selection of an appropriate interpolation method can have a strong influence on resulting DEM quality (Erdogan, 2009; Heritage et al., 2009; Kravchenko and Bullock, 1999; Wise, 2007; Yilmaz, 2007) but recommended methods vary with data density, scale and topography (Chaplot et al., 2006; Desmet, 1997).

Environmental and ecological studies often require assessment of multiple reaches of sometimes highly contrasting nature (e.g. Schwendel et al., in revision). This requires a straightforward generation of DEMs, ideally using the same interpolation method for all reaches to provide consistency and improve comparability between DEMs and derived parameters. Thus an appropriate interpolation method should be suited to consistently generate DEMs that: (1) realistically and accurately represent channels having a range of contrasting substrate and hydraulic conditions; (2) are based on surveys of varying data density and distribution; (3) do not need time consuming site specific adjustments such as development of semi-variograms or introduction of breaklines; and (4) computation time should be manageable. This 
necessarily results in a trade-off between DEM quality of a single dataset and the suitability of a method for many datasets. The literature comprises many comparisons of site specific tailored interpolation methods (e.g. Desmet, 1997; Kravchenko and Bullock, 1999) and recent studies focus on development of new methodologies for data acquisition (e.g. Alho et al., 2009; Hodge et al., 2009), management of data uncertainty (e.g. Wheaton et al., 2010a, b) and multi-scale data retrieval (e.g. Heritage et al., 2009; McMillan and Brasington, 2007). In addition Heritage et al. (2009) have addressed the influence of survey strategy and performance of interpolation methods at a single site, but none of these studies has analysed the performance between contrasting channel environments. This study fills this gap which is important because it facilitates geomorphological and ecological research seeking to compare numerous, contrasting, river reaches and complies with the need of scientists to use morphological budgeting in applied and interdisciplinary studies.

This paper compares seven gridding methods on a range of topographic surveys of four diverse river reaches. DEMs were generated within Surfer ${ }^{\circledR}$, a spatial analysis software widely used for this purpose in geomorphology and other disciplines (e.g. Andrews et al., 2002; Fuller and Hutchinson, 2007; Fuller et al., 2003b; Pilesjö et al., 2006; Schmidt and Persson, 2003; Takken et al., 2001; Yilmaz, 2007). Dynamics of New Zealand headwater streams and processes responsible for the observed changes in topography are discussed elsewhere (Schwendel et al., 2010b).

\section{SITES AND METHODS}

\section{Sites}

Between October 2007 and February 2008 two topographic surveys were completed at four mountain streams in the Ruahine and Tararua Ranges which are located in the southern part of New Zealand's North Island (Figure 1). The hydraulic properties of the reaches varied considerably in terms of slope, width and hydraulic radius as did sediment characteristics (Table I). Topographic characteristics range from relatively smooth, clearly structured gravel-bed streams with low surface roughness (Tamaki) to very bouldery streams with highly structured surfaces (Pukeatua) (Figure 2). Some reaches were laterally confined by vegetated banks (Manawatu) or valley topography (Pukeatua), whereas others migrated in wide floodplains (Tamaki, Waipawa). All catchments were dominated by native forest. 
For comparison of interpolation methods a sample of four surveys representing all four sites was selected (Table II). They cover a wide range of survey area and point density. Reach length was $5-7$ times the recently active channel width in order to include at least one riffle-pool sequence (Keller and Melhorn, 1978; Leopold et al., 1964), however, where strong lateral channel migration seemed realistic a wider zone was surveyed.

\section{Survey}

The aim of the surveys was to generate DEMs from which morphological budgets of the gravel and cobble surface at a bedform scale could be constructed between successive dates. Budgets of this calibre of material are not only of commercial importance (e.g. gravel extraction) but also of ecological interest (e.g. providing an indication of stream bed stability, habitat change and physical disturbance).

Data were acquired using a differential GPS system (R8, Trimble Navigation Limited, Sunnyvale, USA) in RTK mode (cf. Brasington et al., 2000). Where satellite reception was limited topographic data were retrieved with a electronic total station GTS 701 (Topcon Corporation, Tokyo, Japan). To prevent occurrence of multipath errors (Kennedy, 2002) the base station was installed some distance from each reach.

The survey was designed to be terrain sensitive, i.e. point density was highest at breaks in slopes and highly structured surfaces (Fuller et al., 2005). Consequently in highly structured channels point density was higher than in smooth reaches. Substrates larger than cobbles require a grain scale resolution to be represented adequately in a DEM together with gravelly surfaces. As this is impractical for large survey areas, presence of boulders (b-axis $>300 \mathrm{~mm}$ ) was noted during the field survey and they were blanked in the DEM and thus not considered for budgeting. Concomitant tracking of in situ marked boulders showed that only $3 \%$ of them moved during floods. The surveyed surface reflects surface roughness, e.g. no attempt was made to measure at a grain-scale resolution and thus the survey pole was placed on top of stones as well as in gaps between particles. Surveyed areas vary between $132 \mathrm{~m}^{2}$ and $2438 \mathrm{~m}^{2}$ whereas average point density lies between 0.6 and 11.7 points $\mathrm{m}^{-2}$ (Table II). Substrate composition was assessed with the Wolman pebble count method (Wolman, 1954) which measures the b-axis of $>100$ randomly selected substrate particles. They were classified according to a modified Wentworth scale and particle size fractions were calculated (Table I). 
Precision of electronic theodolites or differential GPS systems is high, but due to satellite constellation, atmospheric interference or weather conditions larger errors can occur. These can be assessed with frequent measurements of independent check points during a survey (Brasington et al., 2000) or more accurate data (Fisher and Tate, 2006). Internal quality control data generated by the survey device can also indicate precision of measurements (Fuller and Hutchinson, 2007). Here vertical precision calculated from a limited number of independent check points was $0.015 \mathrm{~m}$ which compares well to vertical error derived from internal quality control data ranging between 0.020 and $0.030 \mathrm{~m}$. Survey error also depends on surface roughness and is often identified by a percentile of the substrate size distribution (Brasington et al., 2000; Chappell et al., 2003). Thus the $84^{\text {th }}$ substrate size percentile of the surveyed bed material assemblage (upper threshold $300 \mathrm{~mm}$ ) $\left(\mathrm{D}_{84 \mathrm{corr}}\right)$ provided an indicator for the error induced by surface roughness. The latter is significantly larger than the above identified instrument precision.

\section{Interpolation}

Data were analysed, interpolated and visualised with Surfer 8.01 (Golden Software, Golden, USA). A grid size of $0.1 \mathrm{~m}$ was chosen which is suitable to account for small scale variation in densely surveyed areas, but still large enough (compared to surface roughness and mean point distances) to avoid the occurrence of spurious artefacts (Brasington and Richards, 1998; Fuller et al., 2003a). Modern software packages offer a wide range of local neighbourhood and geostatistical interpolation methods of which seven were tested: triangulation with linear interpolation, natural neighbours, point kriging without drift, universal kriging, multiquadratic radial basis function, modified Shepard's method and inverse distance to a power. These methods are briefly described in Chaplot et al. (2006), Franke (1982), Fuller et al. (2003a) and Yilmaz (2007). For the inverse power weighting a power of 2 with a search radius including maximal 64 points and no smoothing was applied. The very similar modified Shepard's approach used default values calculated in Surfer for the radii for quadratic fit and distance-weighting (Golden Software, 2002). Kriging was based on the default linear variogram with no nugget effect. All the tested interpolation methods except universal kriging are regarded as exact interpolators. This means the model honours the altitudes of surveyed points if these are lying on a grid node. Furthermore point kriging with linear drift (universal kriging) was also tested because 
a trend following the gradient of the stream was possible, at least for the larger surveys (cf. Fuller et al., 2003a). However, generally no anisotropy was assumed because the length of the reaches was not much greater than the width. All methods are within limits appropriate for irregularly distributed data. For all interpolation methods the dataset specific default values generated in Surfer were used to keep the analysis consistent and comparable. A specification of the gridding methods (e.g. development of variograms for kriging, introduction of breaklines) for each dataset might reveal better DEMs for a single survey but is not practicable with many datasets and beyond the scope of this particular paper.

\section{Comparison of interpolation methods and DEM quality}

Assessment of a DEM relative to the true surface requires more precise data of the surface topography (Wise, 2007), but this is often not available. However, independent topographic survey points can be used for total DEM error estimation if the error in measurement of the check method is accounted for (Brasington et al., 2003). Where independent data are unavailable, DEM quality can be explored using split-sampling (Chaplot et al., 2006; Desmet, 1997; Fisher and Tate, 2006), crossvalidation (Erdogan, 2009) or residual analysis (Fuller and Hutchinson, 2007; Fuller et al., 2003b; Yilmaz, 2007). Residual analysis uses non-independent data but has the advantage over split-sample approaches of not reducing DEM quality, which is important, since the survey was designed to be effective (terrain sensitive) and provide the best possible data for interpolation (cf. Fuller and Hutchinson, 2007). Quality assessment based on thinning of datasets works well with interpolation methods that estimate a local surface as a function of many points (e.g. kriging), but has disadvantages when a local surface depends only on a few neighbouring points (e.g. triangulation). DEM quality is not only defined in terms of vertical accuracy but also in terms of the desired application (e.g. DEM differencing) and derived properties (e.g. slope) (Lane et al., 2003; Wise, 2007). Derivatives like: slope; curvature; estimation of change; or flow routing (Brasington and Richards, 1998; Erdogan, 2009; Lane et al., 2003; Wise, 2007) and comparisons between the DEM and visual observations of the actual surface in check areas with certain properties (e.g. planar surfaces, geometric bedforms) are often used to investigate shape reliability (Desmet, 1997). Visualisation allows semi-quantitative assessment of the DEM quality and is a common method to detect errors in DEMs (Desmet, 1997; 
In a pre-selection phase models of all 4 datasets and each gridding method were visualised with shaded relief maps and contour maps (c.f. Wood and Fisher, 1993). These were qualitatively examined and interpolation methods that did not meet a minimum level of realistic surface representation were excluded from further analysis.

After consideration of linear drift in kriging models, a reduced number of interpolation methods were tested according to the following criteria:

(1) representation of relatively flat planes (e.g. depiction of sediment sheets or channel armour),

(2) representation of the surface of elevated grassy banks to depict their smooth and stable character,

(3) horizontal representation of straight lines (e.g. banks and bar margins),

(4) vertical representation of channel margins (e.g. for assessment of channel crossprofile),

(5) representation of the channel bottom (e.g. gravel bars, pools and steps),

(6) shape of contour lines to depict surface structure appropriately,

(7) representation of longitudinal elements (e.g. continuity of bars, trenches and banks) and

(8) residual analysis (honouring the elevation of measured points).

Additionally DEMs were compared directly (subtraction) with the triangulation model chosen as a reference, because its generation is most intuitive. Differencing of DEMs from two consecutive surveys was employed to investigate the use of different methods in application of morphological budgeting. During visualisation only the relative DEM quality between methods was assessed because survey precision was not accounted for, however, this uncertainty is considered in the discussion. 
DEM quality was evaluated using mean error, standard deviation and mean absolute errors: The Mean Error (ME) is a commonly used measure which can account for the bias in data (systematic error) (Fisher and Tate, 2006) (Eq. 1) where $n$ is the number of data points.

$M E=\frac{\sum\left(Z_{\text {survey }}-Z_{D E M}\right)}{n}$

The standard deviation of the Mean Error (SD) records the magnitude of scatter around zero (Eq. 2).

$S D=\sqrt{\frac{\sum\left[\left(Z_{\text {survey }}-Z_{D E M}\right)-M E\right]^{2}}{n-1}}$

Alternatively the Root Mean Square Error (RMSE) or the Mean Absolute Error (MAE) (Eq. 3) are used to assess the quality of a DEM. If the mean errors are close to zero RMSE and SD are similar, so only the MAE, ME and SD are discussed here.

$M A E=\frac{\sum\left|Z_{\text {survey }}-Z_{D E M}\right|}{n}$

It should be noted that the spatial variation in error was not accounted for in this study because for most methods only reach-averaged data were available.

\section{RESULTS AND DISCUSSION}

\section{Pre-selection}

Models of all 4 datasets and each gridding method were visualised with shaded relief maps and contour maps to rapidly appraise their representation of morphology relative to photographs. The triangulation, kriging, natural neighbours and radial basis function models show adequate representation of the channel surfaces. In contrast the modified Shepard's method produces an overly smooth surface even when no smoothing factor was employed and it also shows poor representation of linear 


\section{Universal kriging}

In a second step the influence of linear drift versus no drift for point kriging DEMs was evaluated on all 4 datasets. The mean difference in residuals is only marginal (less than $21 \mathrm{~nm}$ ). The mean vertical difference between models of the channel is less than $\pm 1 \mathrm{~mm}$ for the stronger small scale structured surveys Manawatu_2 and Pukeatua_1 and less than $\pm 2 \mathrm{~mm}$ in the other two surveys. These differences lay far below surface roughness (cf. Table I). This suggests that the influence of the slope of the valley floor is negligible for surveys of such small longitudinal extent. Hence only point kriging without linear drift is reported in the further evaluation of the methods to avoid unnecessary duplication and detail.

\section{Criteria based comparison between methods}

The remaining four interpolation methods triangulation with linear interpolation, kriging, natural neighbours and radial basis function were subject to criteria based analysis (Table III).

\section{(1) Representation of relatively flat planes. The active floodplain of Tamaki Stream} comprises some reasonably flat patches (Figure 2C in the background). There are no large differences between DEMs, although natural neighbours, kriging and to a certain extent radial basis function tend to create unrealistic island like concentric shapes (bull's eyes) (Figure 4). The DEM generated with kriging seems to produce the most even surface and the triangulation model seems to be most realistic in terms of reproduction of longitudinal structures. No general ranking between these models could be established for this criterion. 
(2) Representation of the ground surface of elevated grassy banks. Elevated grassy banks occur only on the Manawatu site (Figure 2B). Their surface is not even but quite regular. They were incorporated into the surveys to allow for lateral bank erosion and to define a stable boundary for surface interpolation. Point density is relatively coarse due to surface smoothness. Hence it is expected that DEMs represent a relatively flat surface between the points in order to avoid artificial differences between surveys of the same site.

The triangulation model and the natural neighbours DEMs (Figure 5A and B) give the impression of a plane bank as intended. In contrast the other two DEMs (Figure 5C and D) show an undulating surface with higher elevations between points in the longitudinal direction, a classical scalloping effect, also found by Fuller et al. (2003b). The DEM created with radial basis function demonstrates this behaviour also in lateral direction, thus it is the least appropriate interpolation method according to this criterion.

\section{(3) Horizontal representation of straight lines. When linear features like channel} margins were surveyed a point was measured at each bend so that the lines in between should be represented as straight lines. The northern channel bank at the Manawatu site (Figure 5) gives a good example of a very structured channel margin whereas the side walls of the Tamaki (Figure 4) and Waipawa sites are straighter. The performance of the different gridding methods is consistent throughout all these examples. The triangulation DEM (Figure 4A and Figure 5A) connects neighbouring points with a straight line as intended, but looks unrealistic and angular. The natural neighbours DEM (Figure 4B) produces slightly smoother shapes, which look more realistic and may have advantages with respect to the differencing of models over the edgy shapes of the triangulation DEM at the Manawatu site. The other two DEMs (Figure 4 and Figure 5) again show strong (radial basis function) and very strong (kriging) scallopy shapes between points and therefore do not represent linear features well.

(4) Vertical representation of channel margins. The vertical profile of channel margins is usually not straight but has a concave shape with a steeper upper part and a lower gradient at the base. Often the upper point could not be measured directly on the edge because the substrate was over loose. Thus the measured gradient was often 
(5) Representation of the channel bottom. Representation of the channel bottom is one of the most important criteria because here the main changes in sediment budget are likely to occur and bed stability can be detected. The channel bottom was often surveyed in a regular grid between breaklines in surface topography; gravel bars, banks and pools were accounted for with extra points. Thus a DEM should display the latter structures realistically and not add features where they were not surveyed. This is especially relevant for surveys with low point density (e.g. Waipawa_1).

The area in Figure 7 depicts the wet channel and banks of the Waipawa River. This section consists of an upstream run which leads into a riffle with a longitudinal bar in the centre. Downstream follows an elongated pool. The model created with radial basis function differs strongly from the others. It shows unrealistic peaks and holes between measured points. Kriging and natural neighbours DEMs present some bull's eyes, but beside that their representation of the channel floor is relatively similar to that of the triangulation model. The longitudinal bar in the centre is best modelled with triangulation.

(6) Shape of contour lines. As contour line shapes reflect the surface structure, they should resemble natural shapes in a channel. Kriging, natural neighbours and radial basis function produce round shapes which are similar to real channel forms (Figure 6). In case of the radial basis function derived DEMs the surface is often too 
pointy. The edgy appearance of the triangulated shapes shows little resemblance with natural surface shapes and reflects the process of the Delaunay-triangulation (see also Figure 5).

(7) Representation of longitudinal elements. Longitudinal elements like bars, banks and trenches need to be modelled as continuous feature and not as unconnected rows of highs or lows. According to this criterion triangulation performs best, followed by radial basis function DEMs (bars in centre of Figure 7A-D or bottom half of Figure 4A-D). Natural neighbours and especially kriging often produce isolated bull's eyes instead of longitudinal elements.

(8) Analysis of vertical residuals. Deviation of the DEM surface from the measured points is used as a relative measure for how well the interpolation honours the input data. These DEMs showed generally very low deviations (Figure 8). The mean error (Eq. 1) was negatively biased for radial basis function, natural neighbours and triangulation whereas the values for kriging were weakly positive and the absolutely lowest in comparison. The standard deviation of the ME (Eq. 2) varies considerably between sites with no clearly recognisable connection to survey or site characteristics. However, for each survey the magnitude of SD is similar for natural neighbours, triangulation and kriging whereas the dispersion around the ME is much lower for radial basis function. The mean absolute error (Eq. 3) shows a comparable distribution with the exception that triangulation and kriging interchange their ranking. In summary the MAE and SD of radial basis function DEMs were significantly lower than these of the other models. Triangulation and kriging DEMs were close together followed by the natural neighbours DEMs. Thus the analysis of residuals suggests use of radial basis function as a preferential gridding method. It also shows that the methods, although each regarded as exact interpolator, honour survey points to varying degrees. Geostatistical methods such as kriging were suspected to perform less well but showed similar results to a mathematically simple model like triangulation. The spatial distribution of the residuals shows that the highest differences occur for all DEMs on the channel margins, where the modelling is most complicated (Figure 9). 
The criteria based on visualisation, rank triangulation with linear interpolation best (except for contour shape), followed by the natural neighbours method (Table III). In contrast, if just the residuals are considered the radial basis function performs much better than the other methods. However, for the purpose of morphological budgeting it is crucial that surfaces are represented as realistically as possible, not only at survey points but also in between them. Thus triangulation with linear interpolation is the most suitable and consistent method for gridding in a range of streambed environments. This concurs with findings using different approaches to assess interpolation at a single site (Fuller and Hutchinson, 2007; Heritage et al., 2009). Triangulation provides a robust technique which is unaffected by problems like overand undershooting of surfaces near a jump discontinuity (Gibbs phenomenon) (Florinsky, 2002). Furthermore, triangulation with linear interpolation is favoured by a terrain sensitive survey that has high point densities at breaks in surface slope. An introduction of breaklines might have improved the performance of the other methods but when dealing with multiple sites and datasets this would be time intensive. However, the densification of survey points around breaks in slopes minimises this problem.

\section{Direct comparison}

The subtraction of the different DEMs from the triangulation DEM shows that the channel is represented most consistently with differences mainly below $\pm 0.02 \mathrm{~m}$ between the triangulation and the natural neighbours DEM for the Tamaki (Figure 10A-C), Pukeatua (Figure 10D) and Manawatu sites. Kriging-generated DEMs often show more than $0.02 \mathrm{~m}$ difference whereas the radial basis function model exhibits the largest area of more than $0.02 \mathrm{~m}$ difference at these three sites. This is also mirrored in the volumes of the void between the DEMs and the comparison between cross-sections derived from DEMs and independent measurements (Figure 11).

At the Waipawa site kriging is closest to triangulation with differences mainly below $0.05 \mathrm{~m}$. The natural neighbours DEM lies within a vertical distance of mostly less than $0.1 \mathrm{~m}$. In contrast the deviation of the radial basis function DEM is in some areas considerable. As the Waipawa_1 survey has the lowest point density, the change in performance relative to triangulation could be related to that. 
Overall the differences between models are smallest at the Tamaki site (Figure 11) which possesses the lowest surface roughness and few small-scale structures. Here the deviations from the triangulation occur mainly at the channel margins and to a lesser extent on the channel bottom and floodplain $(< \pm 0.02 \mathrm{~m})$ (Figure 10A-C). In contrast differences between methods are more likely to appear at the channel bottom at reaches which are highly structured on a small scale like the Pukeatua site (Figure 10D). This leads to the conclusion that there is no general bias between the methods although the residuals of the DEMs show a small variation in magnitude and direction. Differences between methods are consequently apparent only at small-scale structures and little when compared to surface roughness. The latter is the dominant error component afflicting data acquisition and of similar magnitude than interpolation errors (Schwendel et al., 2010b). Thus an adequate detection threshold can to some degree account for inappropriate model choice.

\section{Comparison in application}

The Tamaki and to a slightly lesser extent Waipawa sites can be regarded as showing responsive behaviour to small and intermediate floods reflecting a degree of intrinsic coupling. Abundant and highly erodible sediments from steep catchments with high erosion rates result in combination with frequent floods in a low channel and substrate stability (Schwendel et al., 2010b). At these reaches DEM differencing is unlikely to detect effects caused by interpolation methods because it is masked by actual surface changes. Hence only the more stable Manawatu site is displayed (Figure 10). All methods show the highest change in topography at the channel margins. This could be due to lateral erosion (often locally initiated by grazing cattle and sheep) or an artefact of interpolation. The fact that it appears almost on the entire southern bank, points towards the latter because no large scale bank erosion was visible there (Figure 2B). Patterns of scour and fill are similar between the methods with the exception that the radial basis DEMs exhibit less scour and fewer zones of no change in the channel. The triangulation DEM shows the smallest volume of change (Figure 12) but within the same order as kriging and natural neighbours. The major source of this discrepancy seems to be representation of the channel margin.

\section{CONCLUSIONS}


Suggestions of optimal interpolation method from previous investigations are equivocal and subjective (Desmet, 1997) and are only valid for certain scales and surface characteristics. However, geomorphological and ecological studies that seek efficient and consistent comparison of sediment budgets derived by DEM differencing between numerous rivers require an interpolation method that allows a realistic representation of the topography of contrasting channels and can deal with varying data density and distribution. Furthermore, a large number of datasets favours approaches that do not need much site-specific parameterisation. This study accounts for these constraints at a river reach scale.

From the range of exact interpolation methods offered in Surfer ${ }^{\circledR}$, triangulation with linear interpolation modelled the varying surfaces and channel shapes most realistically and consistently without the need to introduce breaklines or site specific parameters. It appears that this mathematically simple method is well suited for terrain sensitive surveys and the range of point densities investigated. Under these conditions triangular artefacts are rare and it produces superior results to geostatistical and other local neighbourhood approaches.

Triangulation with linear interpolation is commonly used for generation of DEMs of single sites (e.g. Brasington et al., 2003; Brasington et al., 2000; Fuller and Hutchinson, 2007; Heritage et al., 2009) but it is also very suitable for comparative studies of multiple river reaches with contrasting channel topographies. This leads to the recommendation of triangulation with linear interpolation as a comprehensive and reliable method of DEM generation for environmental and ecological studies that aim to assess spatial variation in erosion and deposition at various scales and for investigation in bed stability between several varying coarse-substrate streams.

\section{ACKNOWLEDGEMENTS}

Field assistance was provided by Caroline Chin, Heike Schwendel, Jay Gedir, Manas Chakraborty, Michael Smith, Rob Buxton and Zoë Dewson who are thanked. The authors thank two anonymous referees for their helpful and constructive comments on earlier versions of this manuscript. 


\section{REFERENCES}

Alho P, Kukko A, Hyyppä H, Kaartinen H, Hyyppä J, Jaakkola A. 2009. Application of boat-based laser scanning for river survey. Earth Surface Processes and Landforms 34: 1831-1838. DOI: 10.1002/esp.1879

Andrews B, Gares PA, Colby JD. 2002. Techniques for GIS modeling of coastal dunes. Geomorphology 48: 289-308.

Ashmore PE, Church MJ. 1998. Sediment transport and river morphology: a paradigm for study. In: Klingeman PC, Beschta RL, Komar PD, Bradley JB (Editors). Gravel bed rivers in the environment. Water Resources Publications, Oregon, pp. 115 - 139.

Brasington J, Langham J, Rumsby B. 2003. Methodological sensitivity of morphometric estimates of coarse fluvial sediment transport. Geomorphology 53: 299-316.

Brasington J, Richards K. 1998. Interactions between model predictions, parameters and DTM scales for topmodel. Computers \& Geosciences 24: 299-314.

Brasington J, Rumsby BT, McVey RA. 2000. Monitoring and modelling morphological change in a braided gravel-bed river using high resolution GPSbased survey. Earth Surface Processes and Landforms 25: 973-990.

Brewer PA, Passmore DG. 2002. Sediment budgeting techniques in gravel-bed rivers. In: Jones SJ, Frostick LE (Editors). Sediment flux to basins: Causes, Controls and Consequences. Special Publication. Geological Society, London, pp. 97 113.

Chaplot V, Darboux F, Bourennane H, Leguedois S, Silvera N, Phachomphon K. 2006. Accuracy of interpolation techniques for the derivation of digital elevation models in relation to landform types and data density. Geomorphology 77: 126141. DOI: 10.1016/j.geomorph.2005.12.010

Chappell A, Heritage GL, Fuller IC, Large ARG, Milan DJ. 2003. Geostatistical analysis of ground-survey elevation data to elucidate spatial and temporal river channel change. Earth Surface Processes and Landforms 28: 349-370.

Desmet PJJ. 1997. Effects of Interpolation Errors on the Analysis of DEMs. Earth Surface Processes and Landforms 22: 563-580. 
Eaton BC, Lapointe MF. 2001. Effects of large floods on sediment transport and reach morphology in the cobble-bed Sainte Marguerite River. Geomorphology 40: 291-309.

Erdogan S. 2009. A comparision of interpolation methods for producing digital elevation models at the field scale. Earth Surface Processes and Landforms 34: 366-376. DOI: 10.1002/esp.1731

Fisher PF, Tate NJ. 2006. Causes and consequences of error in digital elevation models. Progress in Physical Geography 30: 467 - 489.

Florinsky IV. 2002. Errors of signal processing in digital terrain modelling. International Journal of Geographical Information Science 16: 475-501. DOI: $10.1080 / 13658810210129139$

Franke R. 1982. Scattered data interpolation - tests of some methods. Mathematics of Computation 38: 181-200.

Fuller IC, Hutchinson EL. 2007. Sediment flux in a small gravel-bed stream: Response to channel remediation works. New Zealand Geographer 63: 169 180.

Fuller IC, Large ARG, Charlton ME, Heritage GL, Milan DJ. 2003a. Reach-scale sediment transfers: An evaluation of two morphological budgeting approaches. Earth Surface Processes and Landforms 28: 889-903.

Fuller IC, Large ARG, Heritage GL, Milan DJ, Charlton ME. 2005. Derivation of annual reach-scale sediment transfer in the River Coquet, Northumberland, UK. In: Blum MD, Mariott SB, Leclair SF (Editors). Fluvial Geomorphology VII. Special publication of the International Association of Sedimentologists. Blackwell, Oxford, pp. 61 - 74.

Fuller IC, Large ARG, Milan DJ. 2003b. Quantifying channel development and sediment transfer following chute cutoff in a wandering gravel-bed river. Geomorphology 54: 307-323.

Fuller IC, Passmore DG, Heritage GL, Large ARG, Milan DJ, Brewer PA. 2002. Annual sediment budgets in an unstable gravel-bed river: the River Coquet, northern England. In: Jones SJ, Frostick LE (Editors). Sediment flux to basins: Causes, Controls and Consequences. Special Publication. Geological Society, London, pp. 115 - 131.

Golden Software. 2002. Surfer Manual Golden Software, Golden 
Ham DG, Church M. 2000. Bed-material transport estimated from channel morphodynamics: Chilliwack River, British Columbia. Earth Surface Processes and Landforms 25: 1123-1142.

Heritage GL, Fuller IC, Charlton ME, Brewer PA, Passmore DP. 1998. CDW photogrammetry of low relief fluvial features: Accuracy and implications for reach-scale sediment budgeting. Earth Surface Processes and Landforms 23: 1219-1233.

Heritage GL, Milan DJ, Large ARG, Fuller IC. 2009. Influence of survey strategy and interpolation model on DEM quality. Geomorphology 112: 334-344.

Hodge R, Brasington J, Richards K. 2009. In situ characterization of grain-scale fluvial morphology using Terrestrial Laser Scanning. Earth Surface Processes and Landforms 34: 954-968.

Keller EA, Melhorn WN. 1978. Rhythmic spacing and origin of pools and riffles. Geological Society of America Bulletin 89: 723-730.

Kennedy M. 2002. The Global Positioning System and GIS: An introduction. Taylor \& Francis: London

Kravchenko AN, Bullock DG. 1999. A comparative study of interpolation methods for mapping soil properties. Journal of Agronomy 91: 393 - 400.

Lane SN. 2001. The measurement of gravel-bed river morphology. In: Mosley MP (Editor). Gravel Bed Rivers V. New Zealand Hydrological Society, Wellington, pp. $291-337$.

Lane SN, Chandler JH, Richards KS. 1994. Developments in monitoring and modelling small-scale river bed topography. Earth Surface Processes and Landforms 19: 349 - 368.

Lane SN, Westaway RM, Hicks DM. 2003. Estimation of erosion and deposition volumes in a large, gravel-bed, braided river using synoptic remote sensing. Earth Surface Processes and Landforms 28: 249-271. DOI: 10.1002/esp.483

Leopold LB, Wolman MG, Miller JP. 1964. Fluvial Processes in Geomorphology. W. H. Freeman: San Francisco

Martin Y, Church M. 1995. Bed-material transport estimated from channel surveys Vedder River, British-Columbia. Earth Surface Processes and Landforms 20: 347-361.

Matthaei CD, Townsend CR. 2000. Long-term effects of local disturbance history on mobile stream invertebrates. Oecologia 125: 119-126. 
McMillan HK, Brasington J. 2007. Reduced complexity strategies for modelling urban floodplain inundation. Geomorphology 90: 226-243. DOI: 10.1016/j.geomorph.2006.10.031

Milan DJ, Heritage GL, Hetherington D. 2007. Application of a 3D laser scanner in the assessment of erosion and deposition volumes and channel change in a proglacial river. Earth Surface Processes and Landforms 32: 1657-1674. DOI: 10.1002/esp.1592

Pilesjö P, Persson A, Harrie L. 2006. Digital elevation data for estimation of potential wetness in ridged fields--Comparison of two different methods. Agricultural Water Management 79: 225-247.

Poole GC. 2010. Stream hydrogeomorphology as a physical science basis for advances in stream ecology. Journal of the North American Benthological Society 29: 12-25. DOI: 10.1899/08-070.1

Schmidt F, Persson A. 2003. Comparison of DEM data capture and topographic wetness indices. Precision Agriculture 4: 179 - 192.

Schwendel AC, Death RG, Fuller IC. 2010a. The assessment of shear stress and bed stability in stream ecology. Freshwater Biology. 55: 261-281. DOI: 10.1111/j.1365-2427.2009.02293.x

Schwendel AC, Death RG, Fuller IC, Joy MK. in revision. Linking disturbance and stream invertebrate communities - how best to measure bed stability. Journal of the North American Benthological Society.

Schwendel AC, Fuller IC, Death RG. 2010b. Morphological dynamics of upland headwater streams in the southern North Island of New Zealand. New Zealand Geographer. 66: 14-32. DOI: 10.1111/j1745-7939.2010.01170.x

Strahler AN. 1952. Hypsometric (area-altitude) analysis of erosional topography. Bulletin of the Geological Society of America 63: 1117 - 1142.

Takken I, Jetten V, Govers G, Nachtergaele J, Steegen A. 2001. The effect of tillageinduced roughness on runoff and erosion patterns. Geomorphology 37: 1-14.

Westaway RM, Lane SN, Hicks DM. 2000. The development of an automated correction procedure for digital photogrammetry for the study of wide, shallow, gravel-bed rivers. Earth Surface Processes and Landforms 25: 209-226.

Westaway RM, Lane SN, Hicks DM. 2001. Remote sensing of clear-water, shallow, gravel-bed rivers using digital photogrammetry. Photogrammetric Engineering and Remote Sensing 67: 1271-1281. 
Wheaton JM, Brasington J, Darby SE, Merz J, Pasternack GB, Sear D, Vericat D. 2010a. Linking geomorphic changes to salmonid habitat at a scale relevant to fish. River Research and Applications. 26: 469-486. DOI: 10.1002/rra.1305

Wheaton JM, Brasington J, Darby SE, Sear DA. 2010b. Accounting for uncertainty in DEMs from repeat topographic surveys: improved sediment budgets. Earth Surface Processes and Landforms 35: 136-156. DOI: 10.1002/esp.1886 Wise SM. 2007. Effect of differing DEM creation methods on the results from a hydrological model. Computers \& Geosciences 33: 1351-1365. DOI: 10.1016/j.cageo.2007.05.003

Wolman MJ. 1954. A method of sampling coarse river bed material. American Geophysical Union Transactions 35: 951-956.

Wood JD, Fisher PF. 1993. Assessing Interpolation Accuracy in Elevation Models. Ieee Computer Graphics and Applications 13: 48-56.

Yilmaz HM. 2007. The effect of interpolation methods in surface definition: an experimental study. Earth Surface Processes and Landforms 32: 1346-1361. DOI: 10.1002/esp.1473 


\begin{tabular}{|c|c|c|c|c|c|c|}
\hline site & $\begin{array}{l}\text { Stream } \\
\text { order } \\
\text { (Strahler, } \\
\text { 1952) }\end{array}$ & $\begin{array}{l}\text { Slope } \\
\left(\mathbf{m}^{*} \mathbf{m}^{-1}\right)\end{array}$ & $\begin{array}{l}\text { Mean } \\
\text { hydraulic } \\
\text { radius at } \\
\text { bankfull } \\
\text { (m) }\end{array}$ & $\begin{array}{l}\text { Mean } \\
\text { bankfull } \\
\text { width } \\
\text { (m) }\end{array}$ & $\begin{array}{l}\text { Mean } \\
\text { substrate } \\
D_{50}(\mathrm{~mm})\end{array}$ & $\begin{array}{l}\text { Substrate } \\
\text { composition } \\
\text { (in order of } \\
\text { relative } \\
\text { proportion of s } \\
\text { - sand, g - } \\
\text { gravel, c - } \\
\text { cobbles, b - } \\
\text { boulders) }\end{array}$ \\
\hline Waipawa & 3 & 0.032 & 0.481 & 48.6 & 58.5 & $\mathrm{~g}, \mathrm{c}, \mathrm{b}$ \\
\hline Manawatu & 3 & 0.047 & 0.232 & 7.4 & 64.9 & $c, g, b$ \\
\hline Tamaki & 2 & 0.021 & 0.195 & 19.0 & 35.2 & $\mathrm{~g}, \mathrm{c}$ \\
\hline Pukeatua & 3 & 0.047 & 0.912 & 24.2 & 83.9 & $\mathrm{c}, \mathrm{g}, \mathrm{b}$ \\
\hline
\end{tabular}

Table II. Point density and survey area of all surveys between October 2007 and May 2008 (datasets selected for testing interpolation methods are in bold)

\begin{tabular}{|l|r|r|r|r|}
\hline survey & \multicolumn{3}{|c|}{$\mathbf{1}($ October/ November 2007) } & \multicolumn{2}{|c|}{$\mathbf{2}(\mathbf{J a n u a r y} /$ February 2008) } \\
\hline site & \multicolumn{1}{|c|}{ area $\left(\mathbf{m}^{2}\right)$} & point density $\left(\mathbf{m}^{-2}\right)$ & area $\left(\mathbf{m}^{2}\right)$ & point density $\left(\mathbf{m}^{-\mathbf{2}}\right)$ \\
\hline Waipawa & $\mathbf{1 8 9 7 . 2 2}$ & $\mathbf{0 . 5 8}$ & 2437.94 & 1.54 \\
\hline Manawatu & 131.84 & 9.41 & $\mathbf{1 5 9 . 6 9}$ & $\mathbf{1 1 . 7 3}$ \\
\hline Tamaki & 902.64 & 2.05 & $\mathbf{8 8 6 . 2 0}$ & $\mathbf{3 . 8 6}$ \\
\hline Pukeatua & $\mathbf{6 1 3 . 4 9}$ & $\mathbf{1 . 9 5}$ & 1002.41 & 2.11 \\
\hline
\end{tabular}

Table III. Summary of the evaluation of criteria and ranking in brackets ( 1 - most suitable, 4 - least suitable)

\begin{tabular}{|c|c|c|c|c|}
\hline Criterion & Triangulation & $\begin{array}{l}\text { Natural } \\
\text { neighbours }\end{array}$ & Kriging & $\begin{array}{l}\text { Radial basis } \\
\text { function }\end{array}$ \\
\hline (1) planes & Flat (1) & Flat (1) & Flat (1) & Flat (1) \\
\hline (2) banks & Flat (1) & Flat (1) & Undulating (3) & Undulating (4) \\
\hline $\begin{array}{l}\text { (3) horizontal } \\
\text { lines }\end{array}$ & Straight (2) & Realistic (1) & Very scallopy (4) & Scallopy(3) \\
\hline $\begin{array}{l}\text { (4) channel } \\
\text { margins }\end{array}$ & $\begin{array}{l}\text { Steep, straight } \\
\text { (1) }\end{array}$ & Smooth (3) & Smoother (4) & Steep, smooth (2) \\
\hline $\begin{array}{l}\text { (5) channel } \\
\text { bottom }\end{array}$ & Realistic (1) & OK (2) & OK (2) & Poor (4) \\
\hline (6) Contours & Angular (4) & Round (1) & Round (1) & Round, deep (3) \\
\hline $\begin{array}{l}\text { (7) longitudinal } \\
\text { elements }\end{array}$ & Realistic (1) & $\begin{array}{l}\text { Isolated } \\
\text { peaks (3) }\end{array}$ & Spiky (4) & Single peaks (2) \\
\hline (8) residuals & $\mathrm{OK}(2)$ & Highest (4) & OK (2) & Lowest (1) \\
\hline Sum of ranks & 13 & 16 & 21 & 20 \\
\hline
\end{tabular}


Figure 1. Study sites in the southern part of the North Island of New Zealand.

Figure 2. Study reaches: Waipawa (A), Manawatu (B), Tamaki (C) and Pukeatua (D).

Figure 3. DEMs of survey Manawatu_2 generated with modified Shepard's method (A), triangulation with linear interpolation (B), inverse distance to a power of 2 (C) and inverse distance to a power of 1 (D). Arrow indicates flow direction and coordination axes denote easting and northing in $\mathrm{m}$.

Figure 4. Comparison of representation of relatively flat patches of the Tamaki floodplain between gridding methods: triangulation (A), natural neighbours (B), kriging (C), radial basis function (D). The distance between contour lines is $0.02 \mathrm{~m}$.

Figure 5. Comparison of representation of the banks and channel margins at the Manawatu site between gridding methods: triangulation (A), natural neighbours (B), kriging (C), radial basis function (D). The distance between contour lines is $0.1 \mathrm{~m}$, measured points are displayed as crosses.

Figure 6. Comparison of representation of the channel margins at the Tamaki site between gridding methods: triangulation (A), natural neighbours (B), kriging (C), radial basis function (D). The distance between contour lines is $0.02 \mathrm{~m}$, measured points are displayed as crosses.

Figure 7. Comparison of representation of the channel bottom at the Waipawa site between gridding methods triangulation: (A), natural neighbours $(B)$, kriging $(C)$, radial basis function (D). The distance between contour lines is $0.05 \mathrm{~m}$, measured points are displayed as crosses and an arrow indicates flow direction.

Figure 8. Residual analysis: mean error (ME) with error bars indicating the standard deviation (SD) and mean absolute error (MAE) (symbols) between sites and gridding methods 
Figure 9. Spatial distribution of vertical residuals of models generated with triangulation (A), natural neighbours (B), kriging (C) and radial basis function (D) for the Manawatu_2 dataset. Arrow indicates flow direction and coordination axes denote easting and northing in $\mathrm{m}$.

Figure 10. Subtraction of models generated with kriging (A), radial basis function (B) and natural neighbours $(\mathrm{C}, \mathrm{D})$ from triangulation model for Tamaki_2 (A-C) and Pukeatua_1 datasets (D). Arrow indicates flow direction and coordination axes denote easting and northing in $\mathrm{m}$.

Figure 11. Cross-sections derived from different DEMs and independent topographic measurements (“cross-section”): Tamaki (A), Manawatu (B). Shaded areas depict blanked sections in the DEMs because of the presence of boulders (visible at the independent cross-section). Deviations between models and from independent surveys are more accentuated at small-scale structured sites (Manawatu) than at smoother surfaces (Tamaki) but are small compared to survey precision as defined by surface roughness (e.g. $\mathrm{D}_{84}$ is $0.058 \mathrm{~m}$ and $0.158 \mathrm{~m}$ at Tamaki and Manawatu respectively).

Figure 12. Models of change between the datasets Manawatu_1 and Manawatu_2 generated with triangulation (A), natural neighbours (B), kriging (C) and radial basis function (D). Arrow indicates flow direction and coordination axes denote easting and northing in $\mathrm{m}$. 


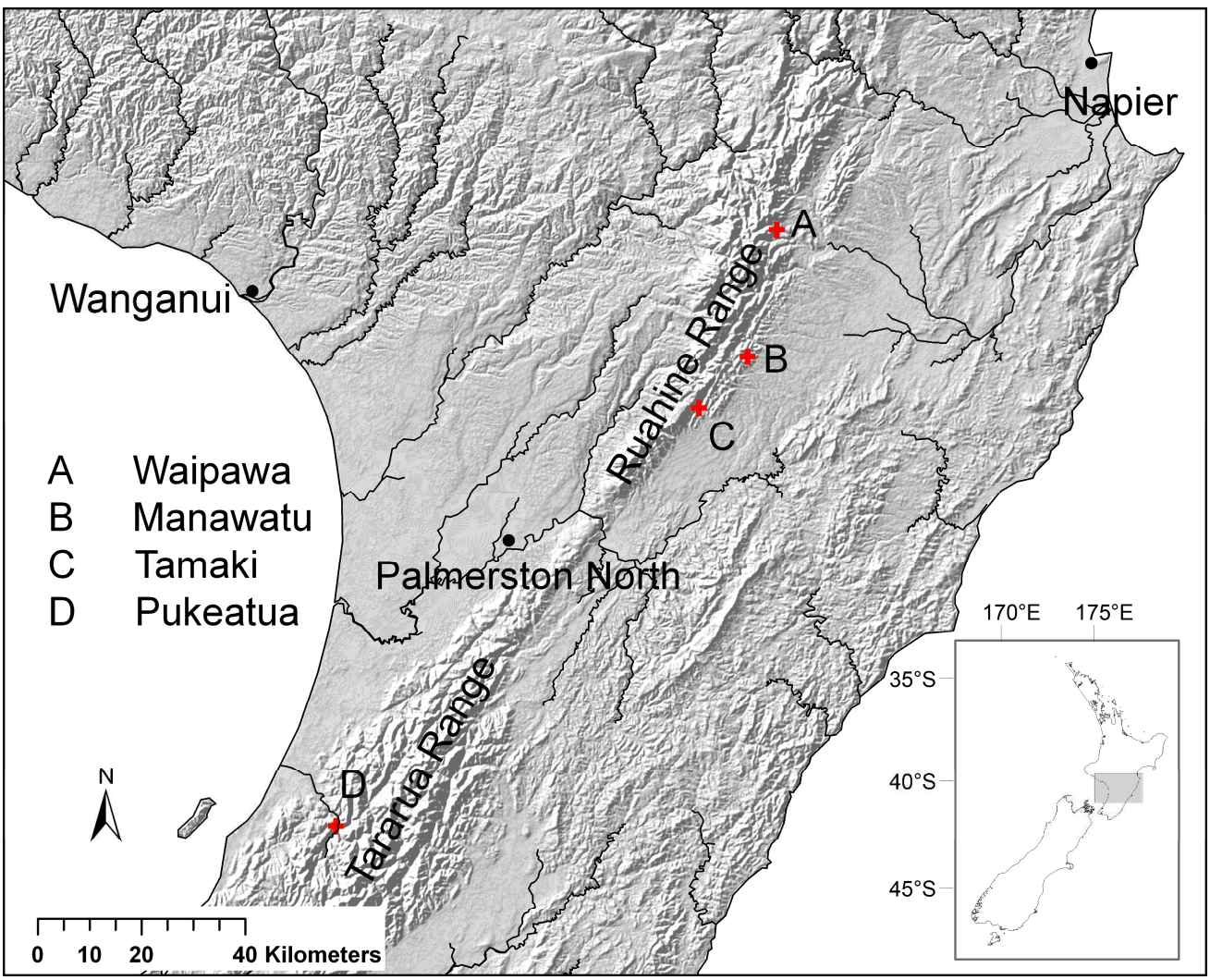

Figure 1. Study sites in the southern part of the North Island of New Zealand. $1112 \times 894 \mathrm{~mm}(96 \times 96 \mathrm{DPI})$ 


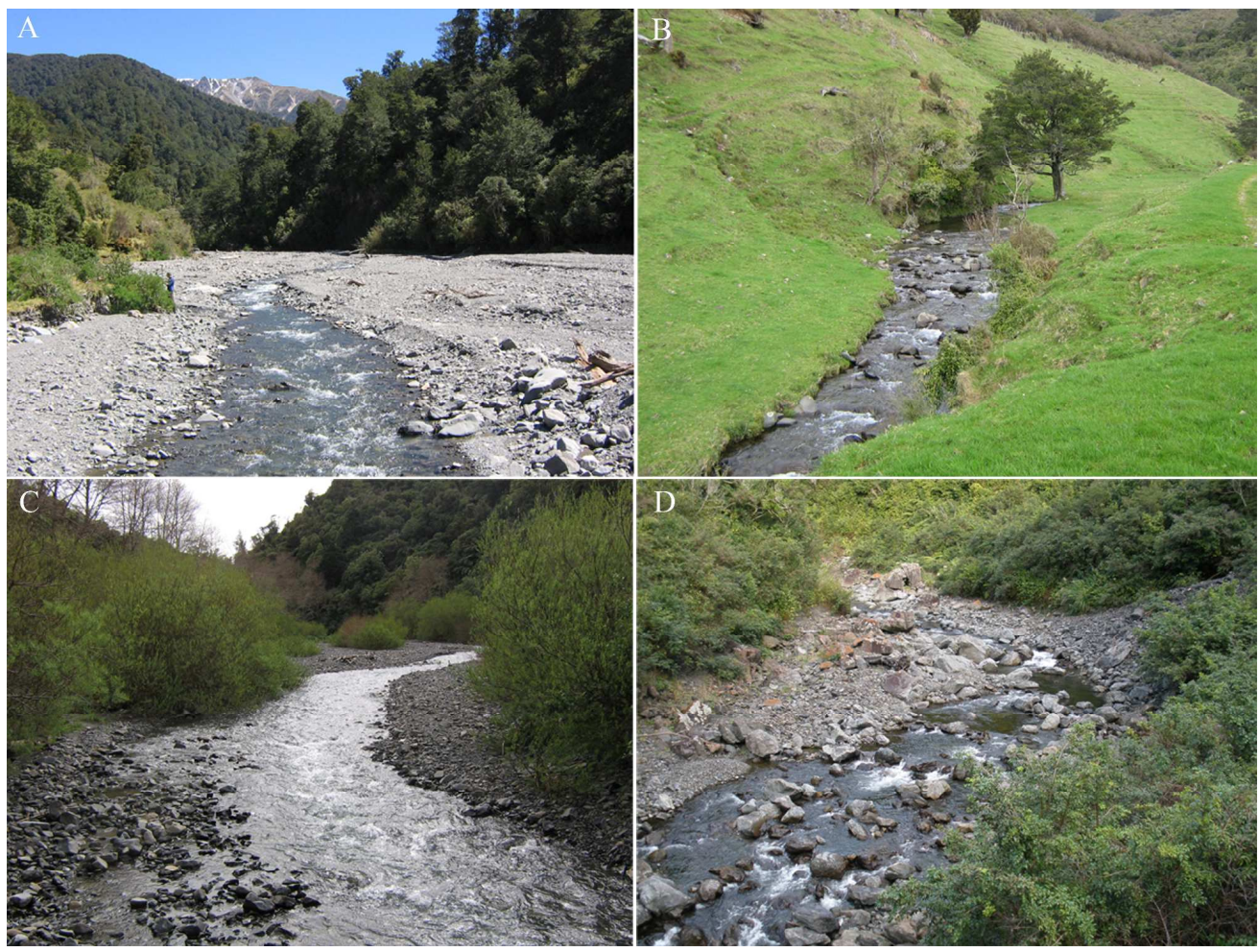

Figure 2. Study reaches: Waipawa (A), Manawatu (B), Tamaki (C) and Pukeatua (D). $170 \times 127 \mathrm{~mm}(600 \times 600 \mathrm{DPI})$ 


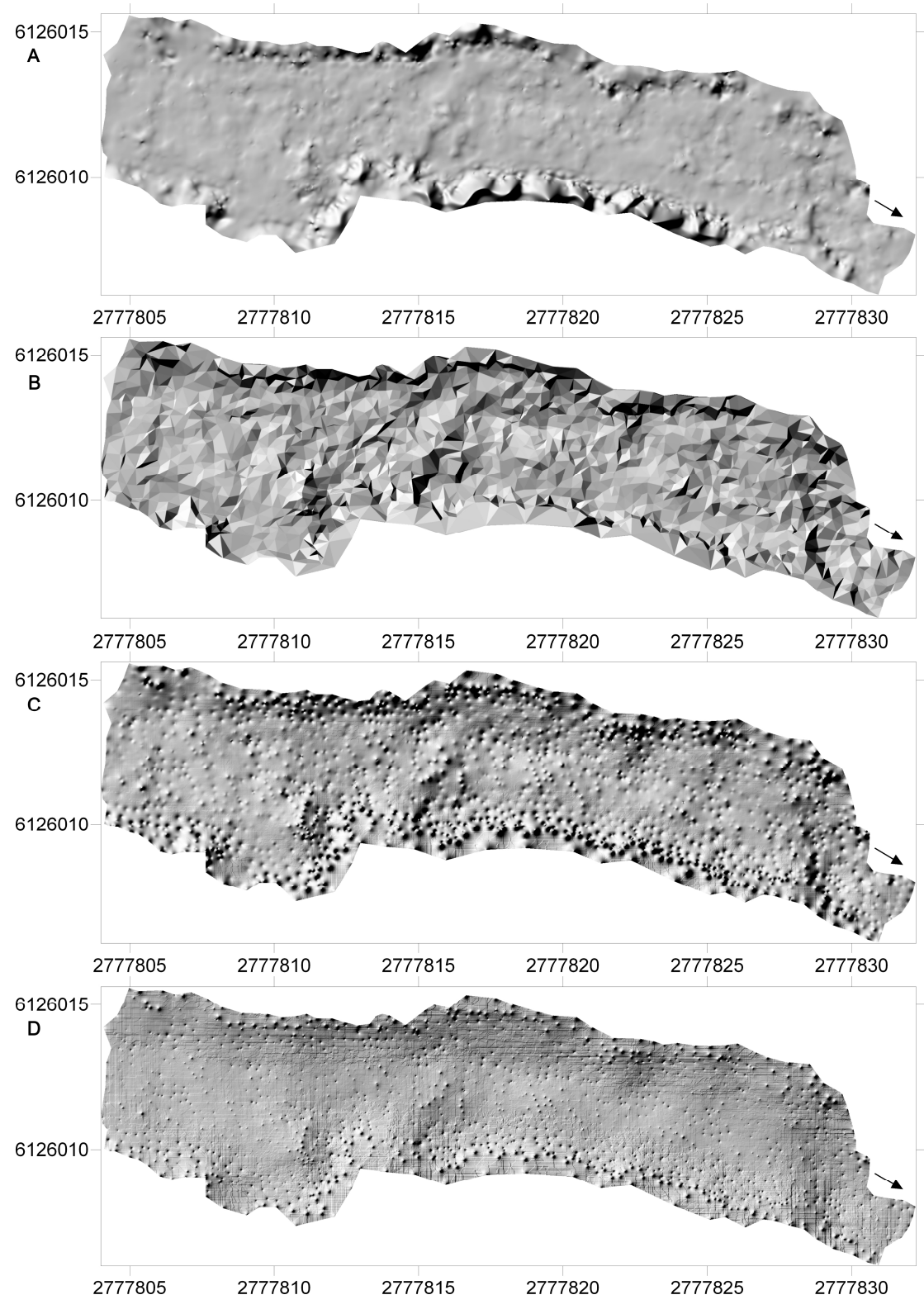

Figure 3. DEMs of survey Manawatu_2 generated with modified Shepard's method (A), triangulation with linear interpolation (B), inverse distance to a power of 2 (C) and inverse distance to a power of 1 (D). Arrow indicates flow direction and coordination axes denote easting and northing in $\mathrm{m}$. $170 \times 241 \mathrm{~mm}(600 \times 600 \mathrm{DPI})$ 


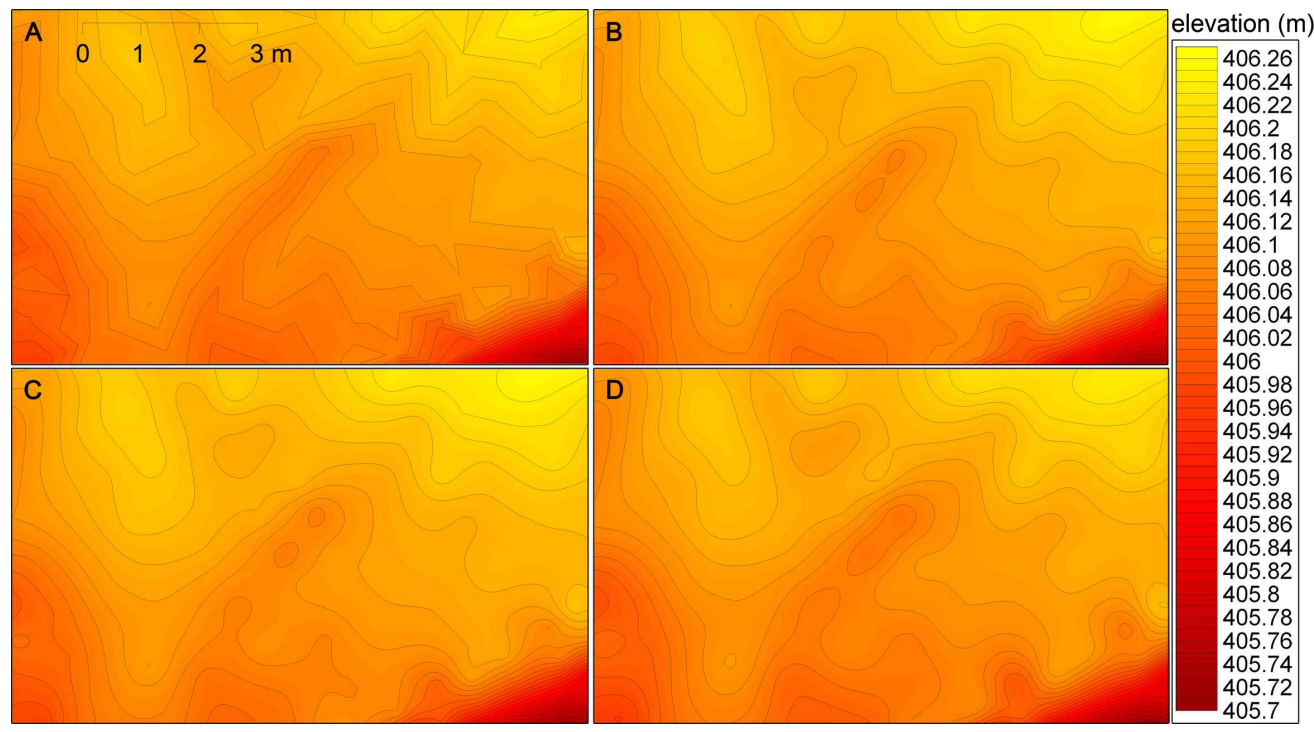

Figure 4. Comparison of representation of relatively flat patches of the Tamaki floodplain between gridding methods: triangulation (A), natural neighbours (B), kriging (C), radial basis function (D). The distance between contour lines is $0.02 \mathrm{~m}$. $98 \times 54 \mathrm{~mm}(600 \times 600$ DPI $)$ 

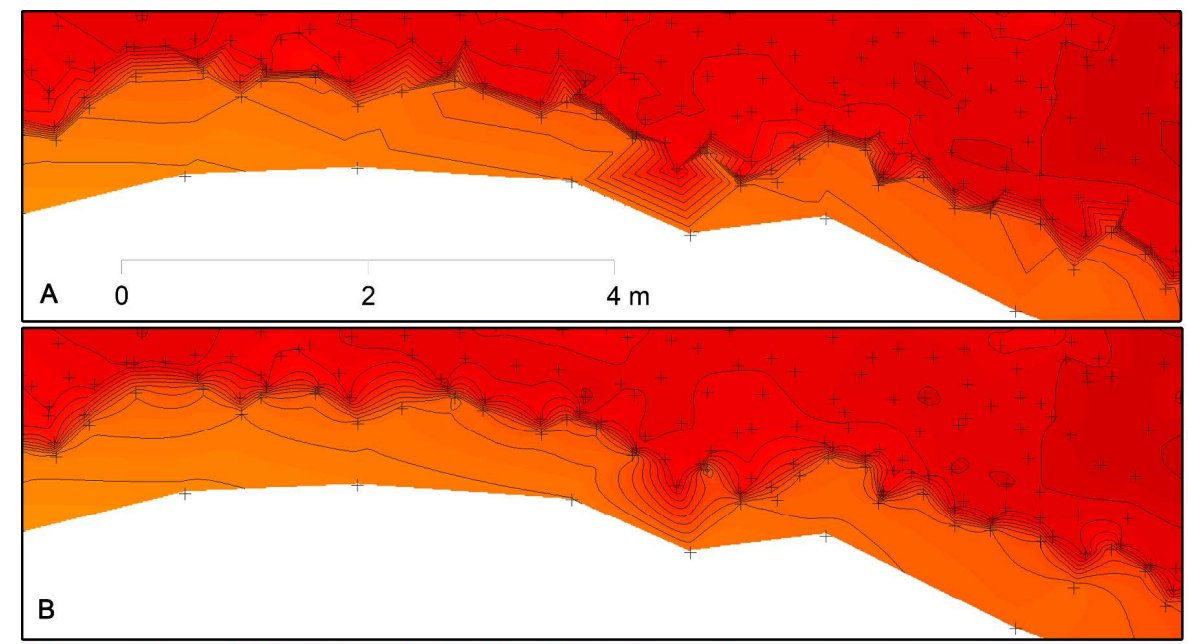

elevation

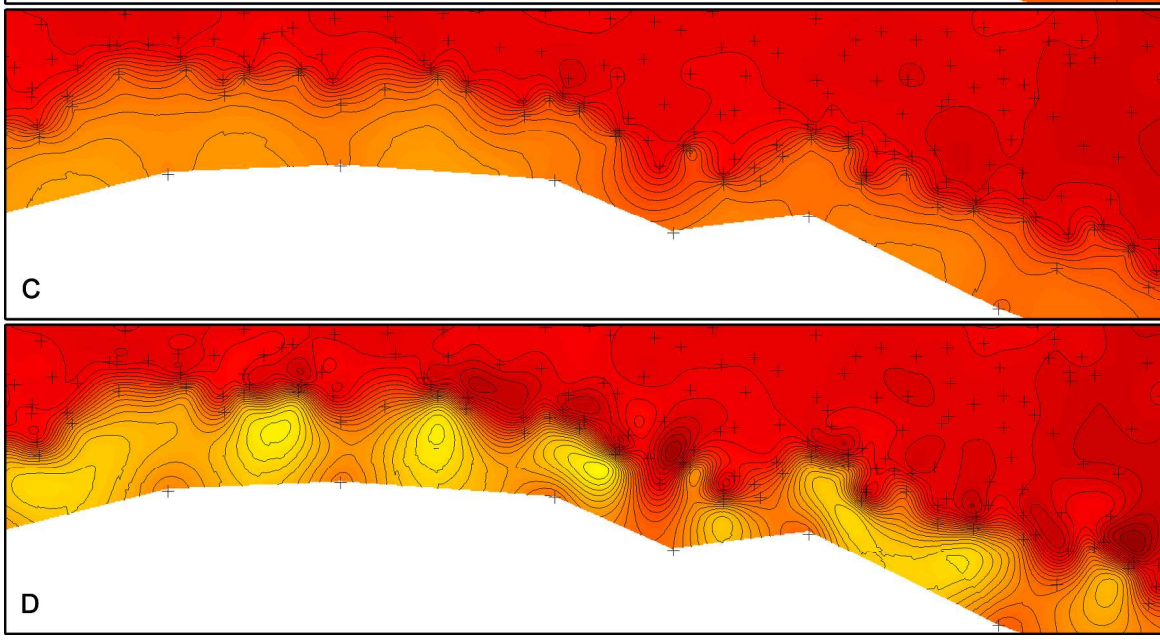

Figure 5. Comparison of representation of the banks and channel margins at the Manawatu site between gridding methods: triangulation $(A)$, natural neighbours $(B)$, kriging $(C)$, radial basis function (D). The distance between contour lines is $0.1 \mathrm{~m}$, measured points are displayed as crosses.

$170 \times 165 \mathrm{~mm}(600 \times 600 \mathrm{DPI})$ 


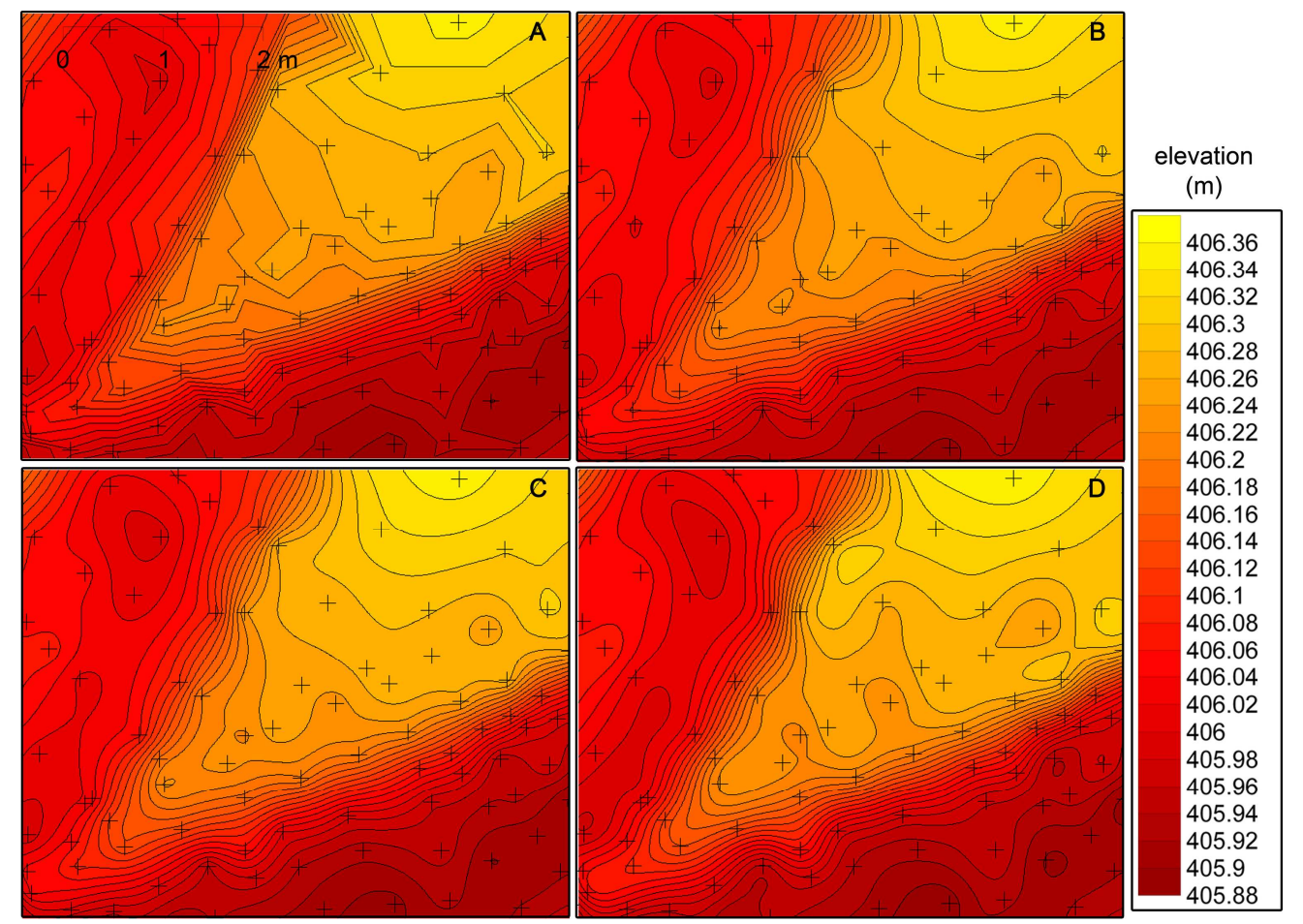

Figure 6. Comparison of representation of the channel margins at the Tamaki site between gridding methods: triangulation ( $A)$, natural neighbours (B), kriging (C), radial basis function (D). The distance between contour lines is $0.02 \mathrm{~m}$, measured points are displayed as crosses. $129 \times 93 \mathrm{~mm}(600 \times 600 \mathrm{DPI})$ 


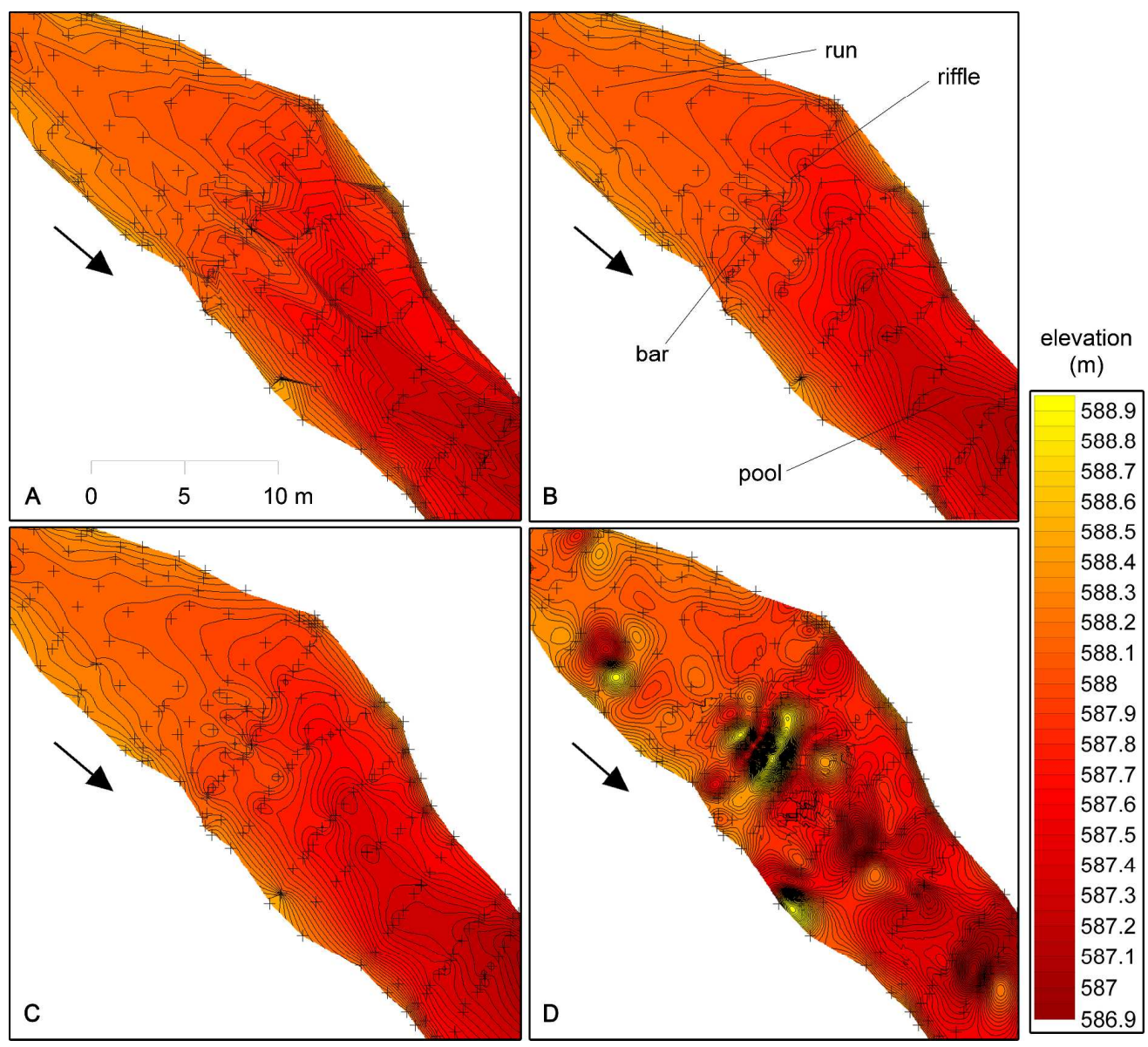

Figure 7. Comparison of representation of the channel bottom at the Waipawa site between gridding methods triangulation: (A), natural neighbours (B), kriging (C), radial basis function (D). The distance between contour lines is $0.05 \mathrm{~m}$, measured points are displayed as crosses and an arrow indicates flow direction. $157 \times 142 \mathrm{~mm}(600 \times 600 \mathrm{DPI})$ 


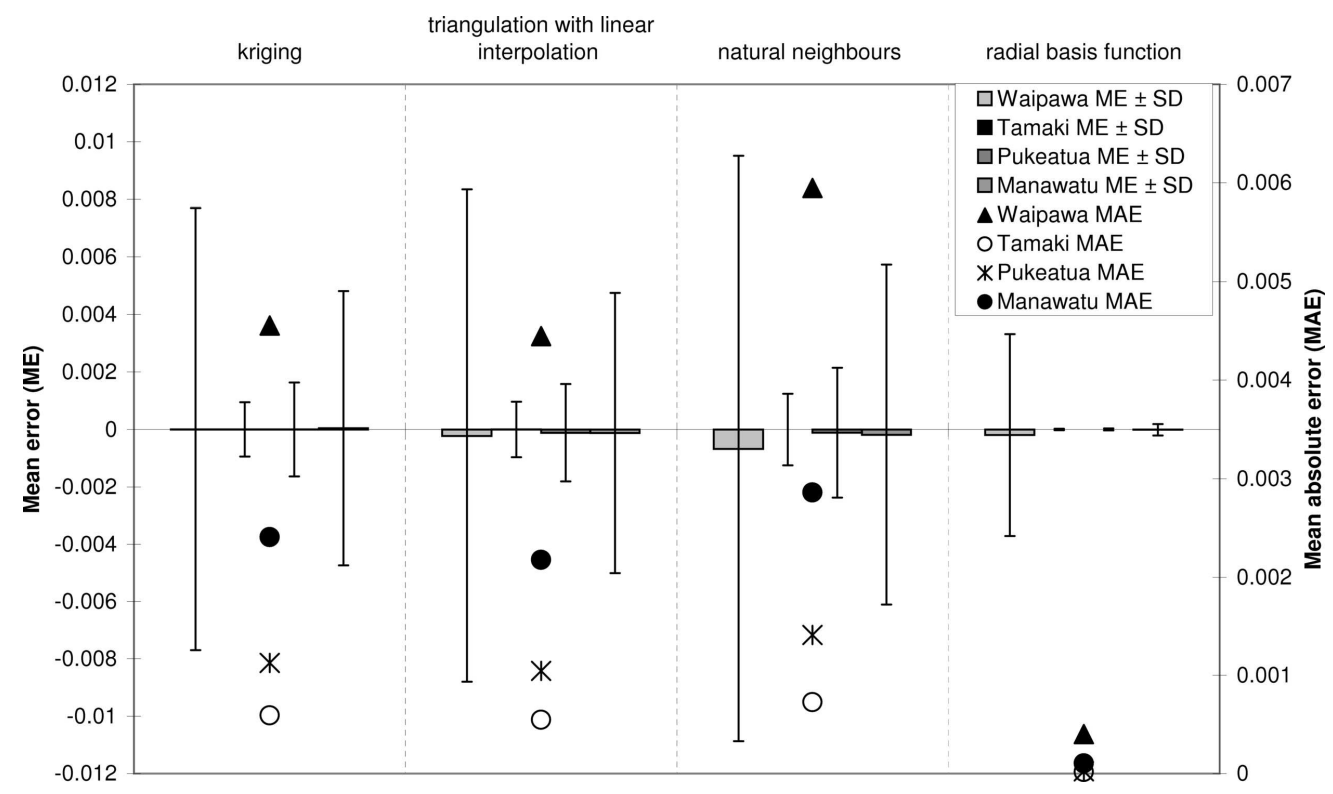

Figure 8. Residual analysis: mean error (ME) with error bars indicating the standard deviation (SD) and mean absolute error (MAE) (symbols) between sites and gridding methods $106 \times 62 \mathrm{~mm}(600 \times 600 \mathrm{DPI})$ 


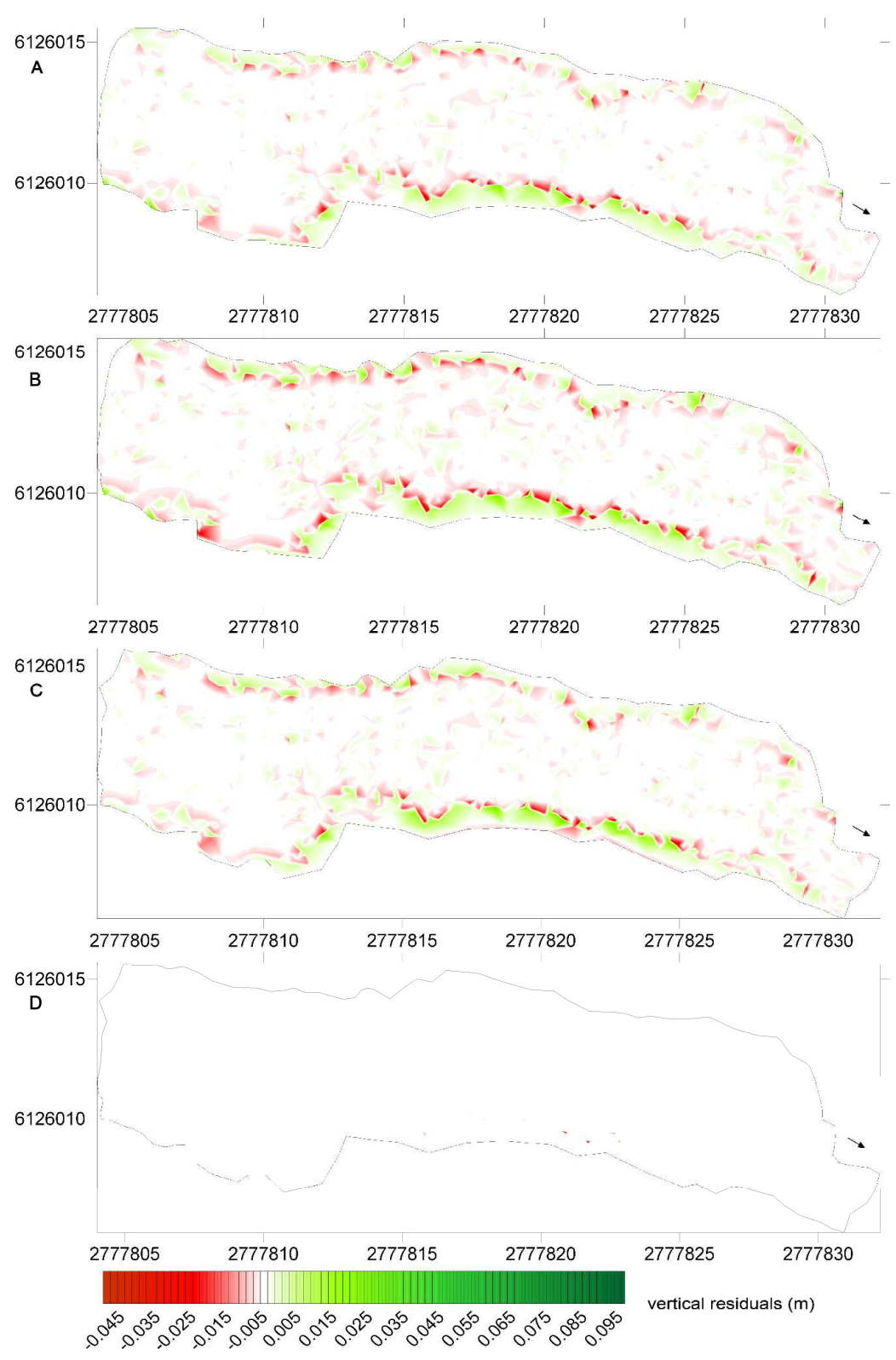

Figure 9. Spatial distribution of vertical residuals of models generated with triangulation (A), natural neighbours (B), kriging (C) and radial basis function (D) for the Manawatu_2 dataset. Arrow indicates flow direction and coordination axes denote easting and northing in $\mathrm{m}$. $170 \times 258 \mathrm{~mm}(600 \times 600 \mathrm{DPI})$ 
Figure 10. Subtraction of models generated with kriging $(A)$, radial basis function $(B)$ and natural neighbours (C, D) from triangulation model for Tamaki_2 (A-C) and Pukeatua_1 datasets (D). Arrow indicates flow direction and coordination axes denote easting and northing in $\mathrm{m}$. $155 \times 134 \mathrm{~mm}(600 \times 600 \mathrm{DPI})$ 


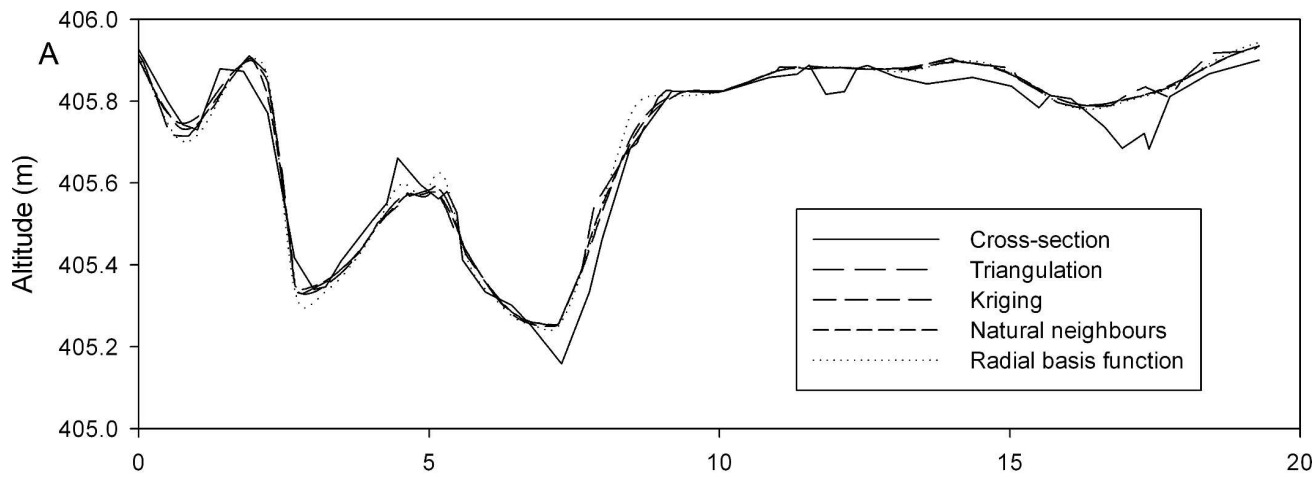

Distance (m)

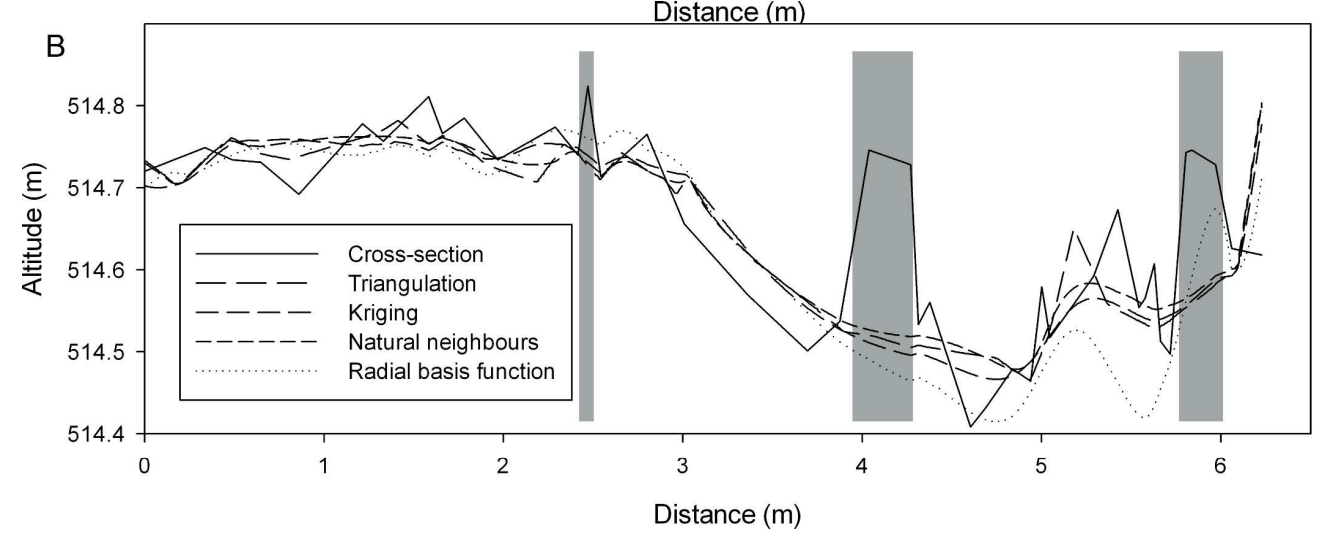

Figure 11. Cross-sections derived from different DEMs and independent topographic measurements ("cross-section"): Tamaki (A), Manawatu (B). Shaded areas depict blanked sections in the DEMs because of the presence of boulders (visible at the independent cross-section). Deviations between models and from independent surveys are more accentuated at small-scale structured sites (Manawatu) than at smoother surfaces (Tamaki) but are small compared to survey precision as defined by surface roughness (e.g. D84 is $0.058 \mathrm{~m}$ and $0.158 \mathrm{~m}$ at Tamaki and Manawatu respectively). $180 \times 140 \mathrm{~mm}(600 \times 600 \mathrm{DPI})$ 


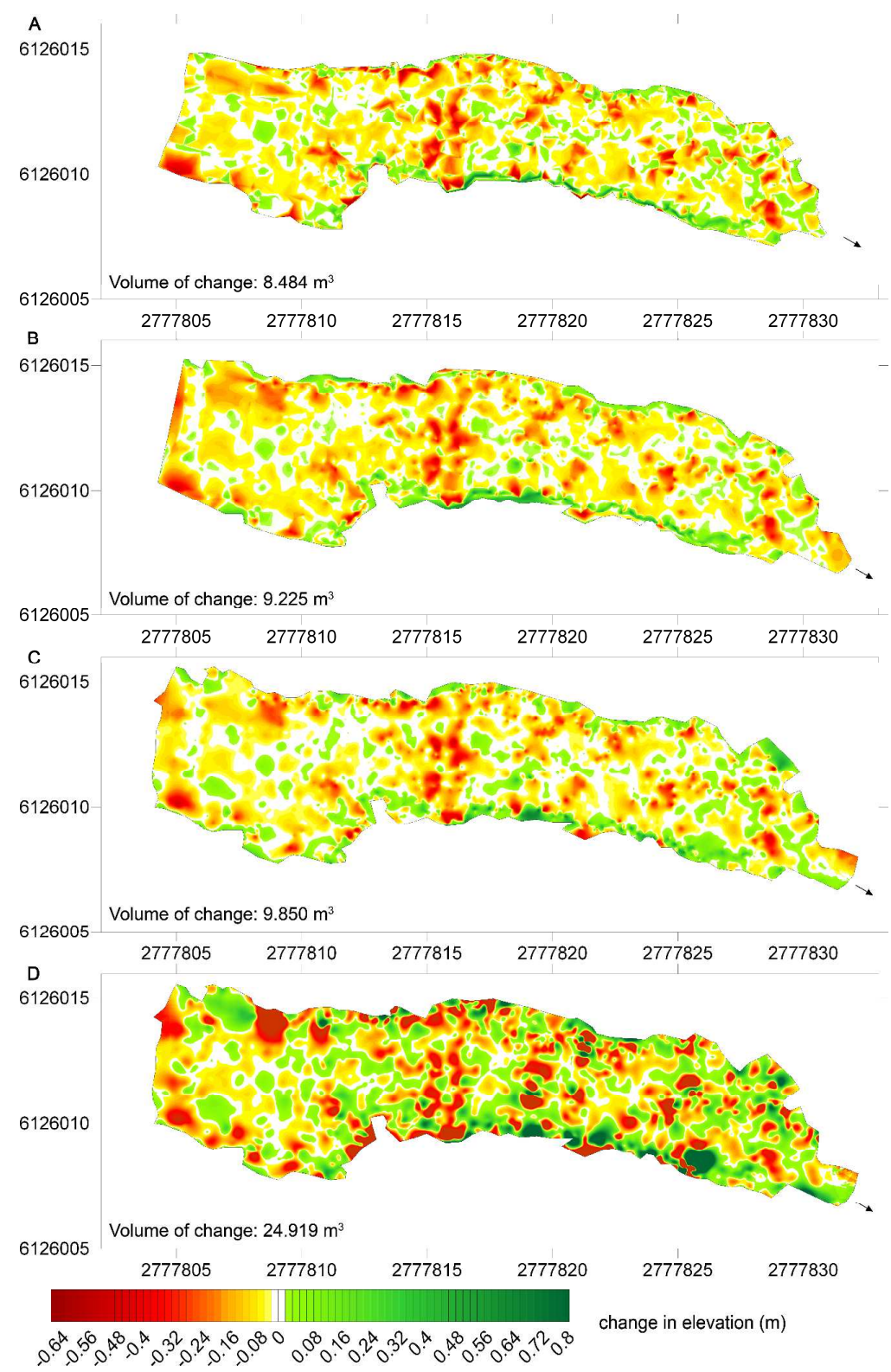

Figure 12. Models of change between the datasets Manawatu_1 and Manawatu_2 generated with triangulation $(A)$, natural neighbours $(B)$, kriging $(C)$ and radial basis function $(\bar{D})$. Arrow indicates flow direction and coordination axes denote easting and northing in $\mathrm{m}$. $170 \times 265 \mathrm{~mm}(600 \times 600 \mathrm{DPI})$ 